\title{
Cognitive and Behavioral Skills Exercises Completed by Patients with Major Depression During Smartphone Cognitive Behavioral Therapy: Secondary Analysis of a Randomized Controlled Trial
}

Toshi A Furukawa ${ }^{1}, \mathrm{MD}, \mathrm{PhD}$; Masaru Horikoshi ${ }^{2}, \mathrm{PhD}$; Hirokazu Fujita ${ }^{3}, \mathrm{MD}, \mathrm{PhD}$; Naohisa Tsujino ${ }^{4}, \mathrm{MD}, \mathrm{PhD}$; Ran Jinnin ${ }^{5}$, MD, PhD; Yuki Kako ${ }^{6}, \mathrm{MD}, \mathrm{PhD}$; Sei Ogawa ${ }^{1}$, MD, PhD; Hirotoshi Sato ${ }^{7}$, MD; Nobuki Kitagawa ${ }^{8}$, MD, $\mathrm{PhD}$; Yoshihiro Shinagawa ${ }^{9}, \mathrm{MD}, \mathrm{PhD}$; Yoshio Ikeda ${ }^{10}$, MD, PhD; Hissei Imai ${ }^{11}, \mathrm{MD}, \mathrm{PhD}$; Aran Tajika ${ }^{11}, \mathrm{MD}, \mathrm{PhD}$; Yusuke Ogawa ${ }^{11}$, MPH, MD, PhD; Tatsuo Akechi ${ }^{1}$, MD, PhD; Mitsuhiko Yamada ${ }^{12}$, MD, PhD; Shinji Shimodera ${ }^{13}$, $\mathrm{MD}, \mathrm{PhD}$; Norio Watanabe ${ }^{11}, \mathrm{MD}, \mathrm{PhD}$; Masatoshi Inagaki ${ }^{14}, \mathrm{MD}, \mathrm{PhD}$; Akio Hasegawa ${ }^{15}, \mathrm{PhD}$

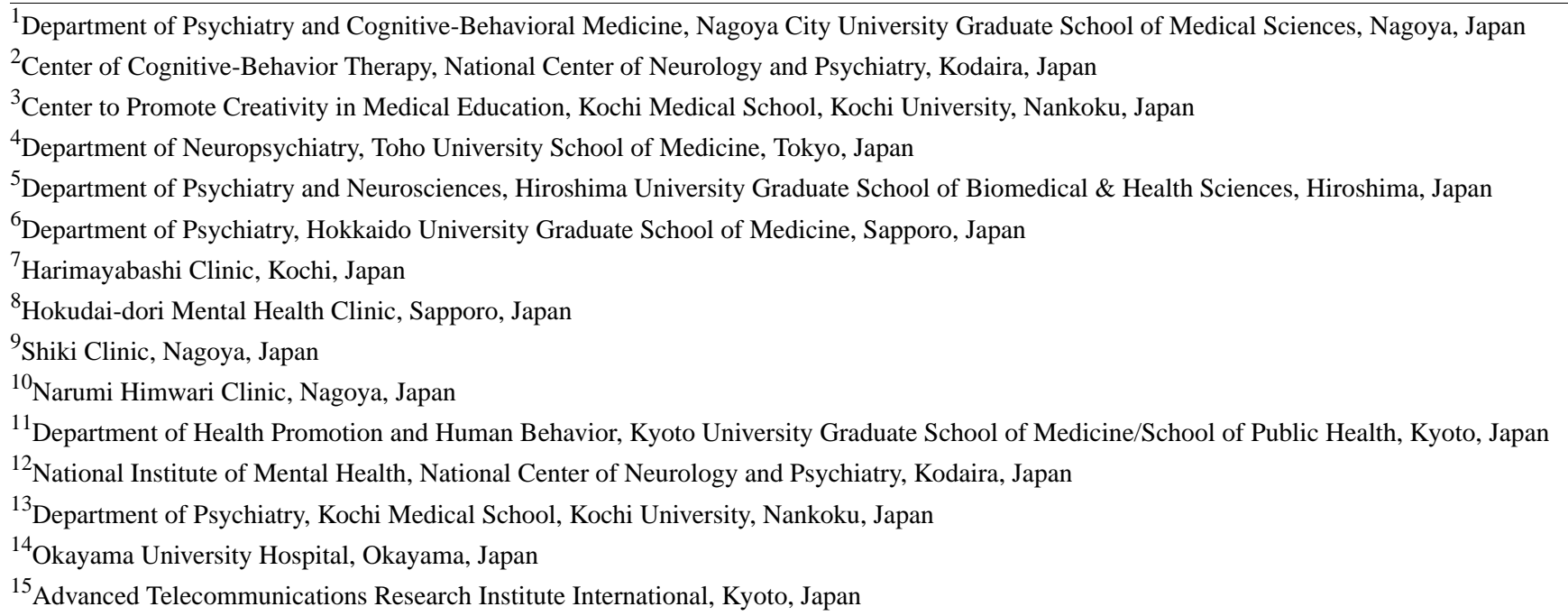

\section{Corresponding Author:}

Toshi A Furukawa, MD, PhD

Department of Psychiatry and Cognitive-Behavioral Medicine

Nagoya City University Graduate School of Medical Sciences

Kawasumi 1, Mizuho-cho, Mizuho-ku,

Nagoya, 467-8601

Japan

Phone: 81527539491

Email: furukawa@kuhp.kyoto-u.ac.jp

\section{Abstract}

Background: A strong and growing body of evidence has demonstrated the effectiveness of cognitive behavioral therapy (CBT), either face-to-face, in person, or as self-help via the Internet, for depression. However, CBT is a complex intervention consisting of several putatively effective components, and how each component may or may not contribute to the overall effectiveness of CBT is poorly understood.

Objective: The aim of this study was to investigate how the users of smartphone CBT use and benefit from various components of the program.

Methods: This is a secondary analysis from a 9-week, single-blind, randomized controlled trial that has demonstrated the effectiveness of adjunctive use of smartphone CBT (Kokoro-App) over antidepressant pharmacotherapy alone among patients with drug-resistant major depressive disorder (total $n=164$, standardized mean difference in depression severity at week $9=0.40$, J Med Internet Res). Kokoro-App consists of three cognitive behavioral skills of self-monitoring, behavioral activation, and cognitive restructuring, with corresponding worksheets to fill in. All activities of the participants learning each session of the 
program and completing each worksheet were uploaded onto Kokoro-Web, which each patient could use for self-check. We examined what use characteristics differentiated the more successful users of the CBT app from the less successful ones, split at the median of change in depression severity.

Results: A total of 81 patients with major depression were allocated to the smartphone CBT. On average, they completed 7.0 (standard deviation [SD] 1.4) out of 8 sessions of the program; it took them 10.8 (SD 4.2) days to complete one session, during which they spent $62 \mathrm{~min}$ (SD 96) on the app. There were no statistically significant differences in the number of sessions completed, time spent for the program, or the number of completed self-monitoring worksheets between the beneficiaries and the nonbeneficiaries. However, the former completed more behavioral activation tasks, engaged in different types of activities, and also filled in more cognitive restructuring worksheets than the latter. Activities such as "test-drive a new car," "go to a coffee shop after lunch," or "call up an old friend" were found to be particularly rewarding. All cognitive restructuring strategies were found to significantly decrease the distress level, with "What would be your advice to a friend who has a similar problem?" found more helpful than some other strategies.

Conclusions: The CBT program offered via smartphone and connected to the remote server is not only effective in alleviating depression but also opens a new avenue in gathering information of what and how each participant may utilize the program. The activities and strategies found useful in this analysis will provide valuable information in brush-ups of the program itself and of mobile health (mHealth) in general.

Trial Registration: Japanese Clinical Trials Registry UMIN CTR 000013693; https://upload.umin.ac.jp/cgi-open-bin/ctr_e/ ctr_view.cgi?recptno=R000015984 (Archived by WebCite at http://www.webcitation.org/6u6pxVwik)

(JMIR Ment Health 2018;5(1):e4) doi: 10.2196/mental.9092

\section{KEYWORDS}

major depressive disorder; smartphone; cognitive therapy; telemedicine

\section{Introduction}

Cognitive behavioral therapy (CBT) is the psychotherapy with the strongest evidence base for the treatment of depression [1-3]. CBT is indeed the only psychotherapy that has been shown to beat the pill placebo condition, the gold standard control condition in the evaluation of medical interventions [4]. It has also been demonstrated to show comparable efficacy as antidepressant pharmacotherapy, which is the mainstay of the treatment for major depression today [5].

The broad umbrella term of CBT, however, now subsumes various and different behavioral and cognitive skills such as self-monitoring, behavioral activation, cognitive structuring, assertion training, structured problem solving, mindfulness, and others [6]. The relative contributions of these various components to the overall efficacy of CBT remain uncertain and debated [7-9]. So-called dismantling studies or component studies to disentangle individual constituents of broadly conceived CBT have been largely underpowered and inconclusive, as each study can only examine the value of adding one particular component in question in a relatively limited number of patients $[10,11]$. Another major issue of such studies is whether the intended components are actually administered by the therapists and received by the patients, although more recent trials attempt to assure their delivery through audio or video recordings.

The development of information and communication technologies, however, is opening new opportunities to monitor the delivery of CBT skills and to study differential contribution of various components of CBT. The CBT itself can be delivered remotely [12], and the patients' progress can be remotely monitored [13,14]. Ecological momentary assessment or experience sampling enables more fine-tuned follow-up of patients' usage of and responses to the program [15,16]. We have developed a smartphone CBT app, named Kokoro-App (kokoro means mind in Japanese), with the integrated Kokoro-Web secure server to which all the activities of the patients with the app are uploaded. Kokoro-App teaches three distinctive CBT skills, namely self-monitoring, behavioral activation, and cognitive restructuring and provides interactive worksheets that the patients can fill in for each task.

The effectiveness of the system was demonstrated in a randomized controlled trial (RCT) comparing antidepressant medication switch plus Kokoro-App against antidepressant medication switch alone among patients who had been unresponsive to one or more antidepressants: the effect size of the intervention was a standardized mean difference of 0.40 in depression severity as measured by masked assessors $(P<.001)$ [17]. This study aims to examine how the patients used the smartphone CBT app during the trial and to investigate what use characteristics differentiated the more successful users of the CBT app from the less successful ones.

\section{Methods}

\section{Study Design}

The original study was a 9-week, multicenter, parallel-group RCT comparing antidepressant medication switch plus smartphone CBT against medication switch alone among patients with antidepressant-resistant depression [17] (Japanese Clinical Trials Registry UMIN CTR 000013693). A total of 164 patients who had not responded to one or more antidepressants at adequate dosage for 4 or more weeks [18] were randomized 1:1 to the intervention or the control arm. The RCT has been registered in the Japanese trials registry (UMIN CTR 000013693). 
The randomized comparison showed that the adjunctive use of smartphone CBT brought about 2.5 (95\% CI 1.2-3.7, $P<.001$ ) points greater reduction in the Patient Health Questionnaire-9 (PHQ-9) [19] scores and 4.1 (95\% CI 1.5-6.6, $P=.002)$ points greater reduction in the Beck Depression Inventory-II [20] scores after 9 weeks [17]. This study focuses on the 81 patients who were randomized to the smartphone CBT arm and describes and analyzes the patients' use of Kokoro-App.

\section{Kokoro-App}

Kokoro-App is a smartphone CBT app and consists of four parts: sessions, mind maps, actions, and thoughts (Figure 1).

There are eight sessions in which several cartoon characters provide psychoeducation through easy but fun conversations. First, the welcome session explains CBT, as well as how to use iPhone and Siri (voice recognition on iPhone). Sessions 1 and 2 explain how to self-monitor one's reactions to various situations according to the cognitive behavioral model. The sessions introduce mind maps in which the patient can enter details of the situation and his reactions to it in terms of emotion and its degree, automatic thoughts, bodily reactions, and behaviors. The patient chooses between four emotions of sad or depressed, anxious or worried, angry, and happy and rates its strength in five grades between 0 and 5 .
Sessions 3 and 4 explain behavioral activation according to two principles of "When the body moves, so does the mind" and "Start small and near." When the patient clicks on actions, lists of candidate activities for behavioral activation personal experiments pop up. The candidates are categorized by the usual time they require to complete into (1) less than 5 seconds, (2) less than $5 \mathrm{~min}$, (3) less than $60 \mathrm{~min}$, and (4) $60 \mathrm{~min}$ or more. The patient chooses a candidate and rates his expected mastery and pleasure levels. When the patient completes the personal experiment, he can enter his achieved mastery and pleasure levels. The patient can also enter his own personal experiment task. After his own experiments, the patient can recommend certain activities by clicking on "Nice!" button and the number of "Nice!"s will be shared by all the patients.

Sessions 5 and 6 explain cognitive restructuring. After providing a rationale for cognitive restructuring, the app provides four interactive items to guide the patient to alternative thoughts. The patient first picks up a mind map to work on. The first item, "fact glasses," asks classic questions about evidence for and evidence against the automatic thought, such as "What facts do you have to support this thought?" and "What facts are there that do not support this thought?" Then the item combines the patient's answers automatically and says, "So you believe XXX but YYY. If you think this way, how do you feel now?" and asks the patient to rerate his feeling.

Figure 1. A screenshot from Kokoro-App.

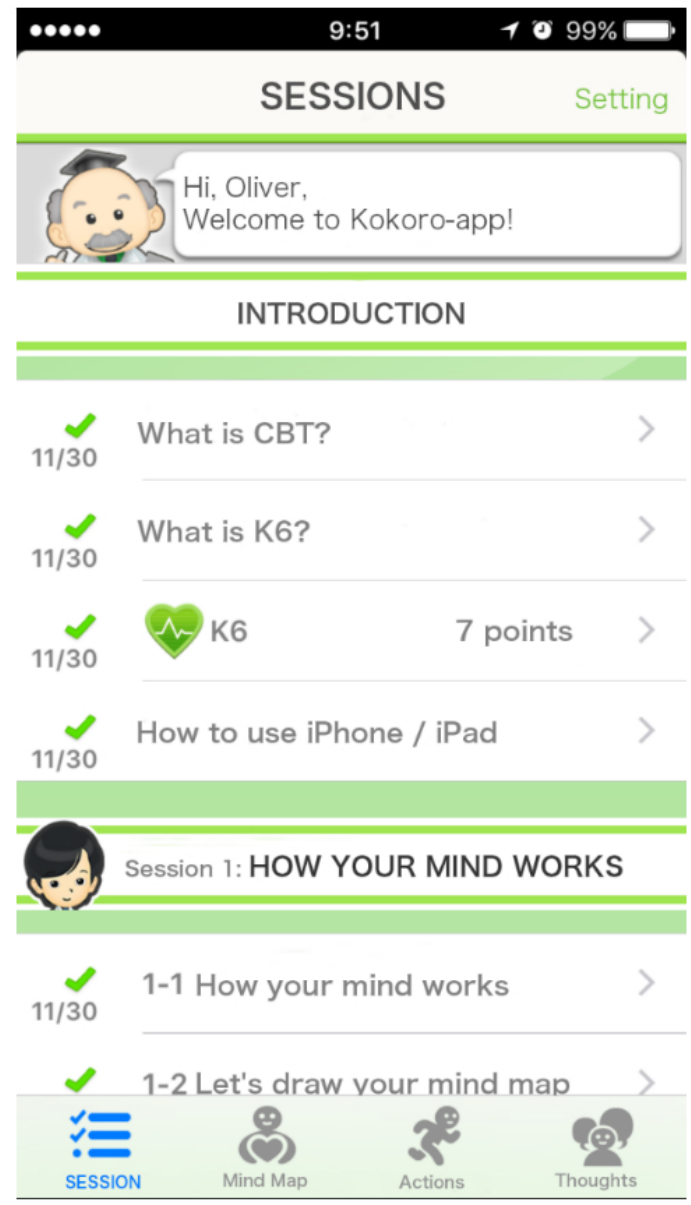


Figure 2. A screenshot from Kokoro-Web.

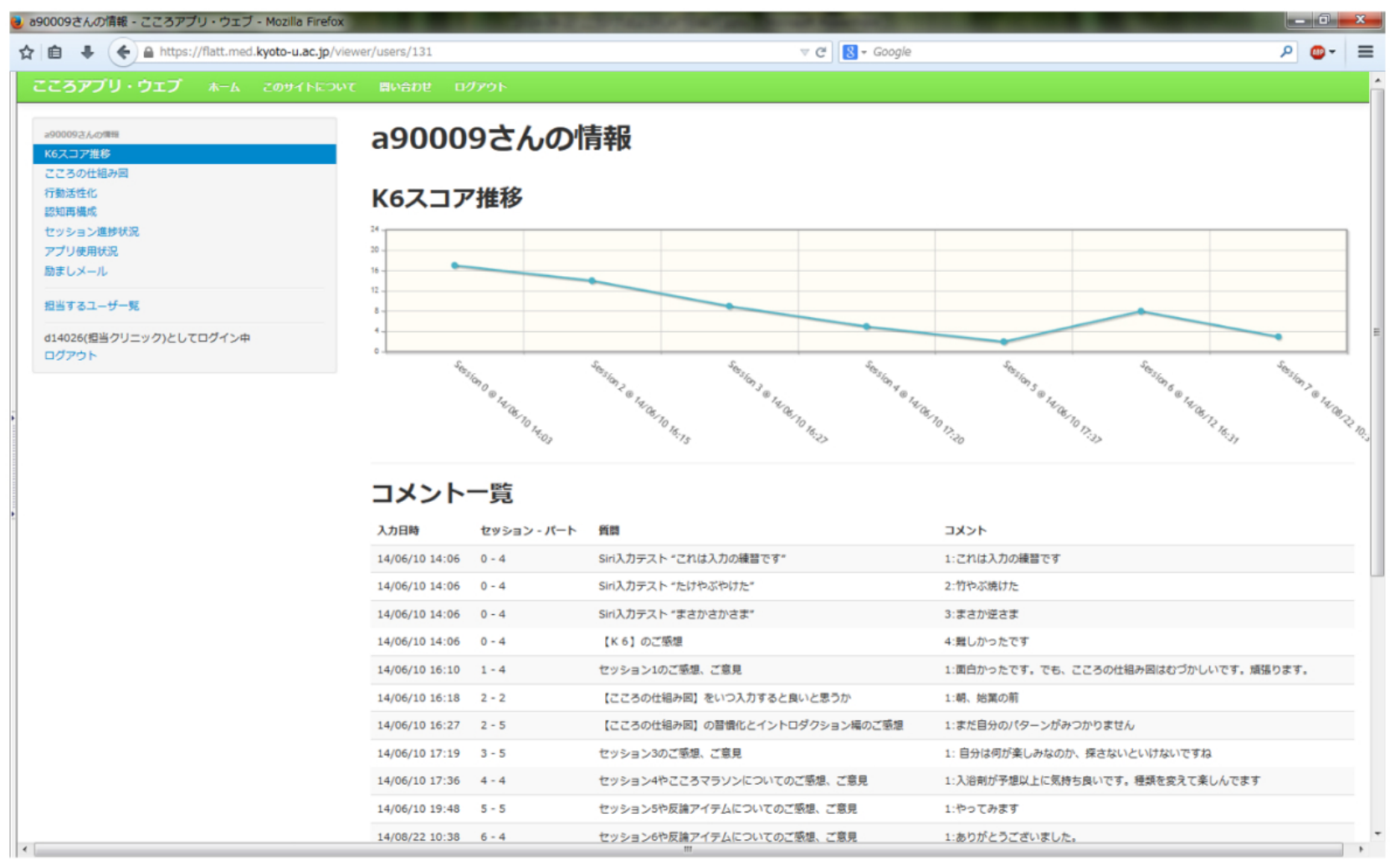

The second item is called "\% Calculator," which does similar things as the fact glasses. It asks, "How confident are you in your thought AAA?" then lets the patient choose between $1 \%$ and $99 \%$. Then it asks, "So you think your thought AAA is $99 \%$ correct. But then what can there be in your other $1 \%$ ?" The patient will then answer XXX, and the item will then ask, "So if you think XXX, how would you feel now?" The third item is "friend's call." The item says, "Ring, ring, ring. You have just received a phone call from your best friend, saying AAA. What advice would you give to her?" The rest is the same. The last item is "What-now microphone." The item goes, "Let's just suppose that your thought AAA is true. If so, what can be done now?" The patient will then make an action statement, and the item will then ask, "What if you did do XXX, how would you be feeling?"

The epilogue session summarizes all the previous sessions and also provides tips for relapse prevention.

Each session is expected to take 1 week. The new session can be opened only a week after the last session was started and after one homework has been completed.

\section{Kokoro-Web}

All the activities of the patient with Kokoro-App are uploaded to the central server and can be viewed on Kokoro-Web (Figure 2) by the patient, as well as by his treating physician. Kokoro-Web was developed seamlessly and integratively with Kokoro-App. The communication between the app and the server through the Internet was certificated by Secure Sockets Layer.

\section{Statistical Analyses}

We first present the descriptive details of how the patients utilized Kokoro-App. The continuous outcomes are summarized by mean and SD and the dichotomous outcomes by number and percentage.

We next subdivide the patients into beneficiaries and nonbeneficiaries from Kokoro-App at the median change score of the PHQ-9 and compare each group's use of the Kokoro-App. Because the same patient contributed a variable number of mind maps, behavioral activations, or cognitive restructurings to account for the within-person clustering effect, we used the mixed effects model where appropriate. Given the observational and hypothesis-generating nature of this study, we set the threshold for statistical significance for each comparison at nominal $P<.05$ throughout. We used STATA (StataCorp) version 14.

\section{Results}

\section{Patient Characteristics}

Table 1 summarizes the baseline demographic and clinical characteristics of the cohort. Patients were typically around 40 years of age, had some higher education, slightly more than half were in some employment, and slightly less than half were married. They had had several depressive episodes, had been in the current depressive episode for almost 2 years, and were in moderately to severely depression at baseline. 
Table 1. Baseline demographic and clinical characteristics of the cohort.

\begin{tabular}{|c|c|}
\hline Characteristics & Mean $\mathrm{SD}^{\mathrm{a}}$ or $\mathrm{n}(\%)$ \\
\hline \multicolumn{2}{|l|}{ Demographic } \\
\hline Age (years), mean (SD) & $40.2(8.8)$ \\
\hline Women, n (\%) & $46(57)$ \\
\hline Education (years), mean (SD) & $14.6(2.5)$ \\
\hline \multicolumn{2}{|l|}{ Employment status } \\
\hline Employed full-time, n (\%) & $34(42)$ \\
\hline Employed part-time, n (\%) & $7(9)$ \\
\hline On medical leave, n (\%) & $21(26)$ \\
\hline Housewife, $\mathrm{n}(\%)$ & $6(7)$ \\
\hline Student, n (\%) & $0(0)$ \\
\hline Retired, n (\%) & $0(0)$ \\
\hline Not employed, n (\%) & $13(16)$ \\
\hline \multicolumn{2}{|l|}{ Marital status } \\
\hline Single, never married, n $(\%)$ & $34(42)$ \\
\hline Single, divorced, separated or widowed, $\mathrm{n}(\%)$ & $13(16)$ \\
\hline Married, n (\%) & $34(42)$ \\
\hline \multicolumn{2}{|l|}{ Clinical } \\
\hline Age of onset at first episode (years), mean (SD) & $31.8(10.8)$ \\
\hline Number of previous depressive episodes, mean (SD) & $3.4(4.9)$ \\
\hline Length of current episode (months), mean (SD) & $24.2(46.3)$ \\
\hline PHQ- $9^{b}$ at baseline, mean (SD) & $13.5(5.5)$ \\
\hline BDI-II ${ }^{\mathrm{c}}$ at baseline, mean (SD) & $28.2(11.2)$ \\
\hline
\end{tabular}

${ }^{\mathrm{a}} \mathrm{SD}$ : standard deviation.

${ }^{b}$ PHQ-9: Patient Health Questionnaire-9.

${ }^{\mathrm{c}}$ BDI-II: Beck Depression Inventory 2nd edition.

\section{Kokoro-App Use Statistics}

Table 2 shows the use statistics of Kokoro-App by the 81 patients.

On average, the patients completed 7.0 out of 8 sessions; it took them 10.8 days to complete one session, during which they spent 62 min on the app reading the sessions and also completing their respective homework (self-monitoring, behavioral activation, or cognitive restructuring).

They filled in 10 mind maps, more often for sad or depressed, or anxious or worried feelings but also for angry or happy feelings. They performed 14 behavioral activation personal experiments through which they had anticipated and achieved moderate levels of mastery and pleasure. With respect to cognitive restructuring, they generated an average of six alternative thoughts using fact glasses, \% Calculator, friend's call, or what-now microphone almost equally frequently.

\section{Behavioral Activations}

We analyzed the behavioral activations completed by the patients according to their frequencies, the level of mastery and pleasure they achieved, and how unexpectedly good they were.

The most frequently chosen behavioral activations were, in the descending order, "Listen to favorite music," "Read books and magazines," "Brew and drink coffee," and so on (Table 3). The levels of mastery or pleasure expected or achieved were typically in the range 3 to 5 on a scale of 0 to 10 .

However, when selected for the levels of achieved mastery or pleasure, very different sets of activities emerged (Tables 4 and 5). These tables are limited to such activities that were reported at least three times. Activities that achieved very high levels of mastery or pleasure included "Test-drive a new car," "Go to a coffee shop after lunch," "Call up an old friend," and "Exercise." 
Table 2. Use statistics of Kokoro-App.

\begin{tabular}{|c|c|}
\hline Use statistics & Mean $\left(\mathrm{SD}^{\mathrm{a}}\right)$, range, and median \\
\hline \multicolumn{2}{|l|}{ Overall } \\
\hline Sessions completed, mean (SD), range & $7.0(1.4), 1-8$ \\
\hline Days taken to complete one session, mean (SD), range & $10.8(4.2), 6.3-31$ \\
\hline Actual time (min) per session, mean (SD), range, median & $62.3(96.30), 0-677,39$ \\
\hline \multicolumn{2}{|l|}{ Self-monitoring } \\
\hline Mind maps, no. completed per person, mean (SD), range & $10.4(10.5), 0-45$ \\
\hline \multicolumn{2}{|l|}{ Mind maps, no. completed per person, by emotion } \\
\hline Sad or depressed, mean (SD), range & $3.2(3.7), 0-16$ \\
\hline Anxious or worried, mean (SD), range & $3.0(3.3), 0-18$ \\
\hline Angry, mean (SD), range & $2.4(3.4), 0-16$ \\
\hline Happy, mean (SD), range & $1.9(3.1), 0-20$ \\
\hline \multicolumn{2}{|l|}{ Level of emotion recorded (on a scale of $0-5$ ) } \\
\hline Sad or depressed, mean (SD) & $3.4(1.3)$ \\
\hline Anxious or worried, mean (SD) & $3.5(1.3)$ \\
\hline Angry, mean (SD) & $3.5(1.3)$ \\
\hline Happy, mean (SD) & $3.2(1.3)$ \\
\hline \multicolumn{2}{|l|}{ Behavioral activation } \\
\hline Behavioral activations, no. completed per person, mean (SD), range & 13.8 (17.3), $0-118$ \\
\hline \multicolumn{2}{|l|}{ Level of mastery or pleasure by behavioral activation (on a scale of 0-10) } \\
\hline Mastery expected, mean (SD) & $4.5(2.8)$ \\
\hline Mastery achieved, mean (SD) & $4.3(3.0)$ \\
\hline Pleasure expected, mean (SD) & $4.8(2.7)$ \\
\hline Pleasure achieved, mean (SD) & $4.7(2.9)$ \\
\hline \multicolumn{2}{|l|}{ Cognitive restructuring } \\
\hline Cognitive restructuring, no. completed per person, mean (SD), range & $6.2(6.3), 0-31$ \\
\hline \multicolumn{2}{|l|}{ Cognitive restructuring items used, per person } \\
\hline Fact glasses, mean (SD), range & $2.0(2.0), 0-11$ \\
\hline$\%$ Calculator, mean (SD), range & $1.5(1.8), 0-10$ \\
\hline Friend's call, mean (SD), range & $1.5(1.6), 0-7$ \\
\hline What-now microphone, mean (SD), range & $1.4(1.5), 0-7$ \\
\hline
\end{tabular}

${ }^{\mathrm{a}} \mathrm{SD}$ : standard deviation. 
Table 3. Behavioral activations: top 10 activities in terms of frequency and their mastery or pleasure levels.

\begin{tabular}{|c|c|c|c|c|c|}
\hline \multirow[t]{2}{*}{ Activity } & \multirow[t]{2}{*}{ Frequency (number of reports) } & \multicolumn{2}{|l|}{ Mastery } & \multicolumn{2}{|l|}{ Pleasure } \\
\hline & & $\begin{array}{l}\text { Expected } \\
\text { Mean }\left(\mathrm{SD}^{\mathrm{a}}\right)\end{array}$ & $\begin{array}{l}\text { Achieved } \\
\text { Mean (SD) }\end{array}$ & $\begin{array}{l}\text { Expected } \\
\text { Mean (SD) }\end{array}$ & $\begin{array}{l}\text { Achieved } \\
\text { Mean (SD) }\end{array}$ \\
\hline Listen to favorite music & 95 & $5.2(3.0)$ & $5.0(3.3)$ & $5.9(2.7)$ & $5.7(2.9)$ \\
\hline Read books and magazines & 71 & $4.9(3.0)$ & $4.5(3.3)$ & $5.3(2.7)$ & $4.8(2.8)$ \\
\hline Brew and drink coffee & 50 & $3.5(3.2)$ & $3.1(2.6)$ & $3.8(2.2)$ & $3.8(2.5)$ \\
\hline Hum a tune & 41 & $2.9(2.5)$ & $2.3(1.9)$ & $3.8(2.1)$ & $3.4(2.2)$ \\
\hline Take a long bath & 36 & $3.6(2.0)$ & $3.9(2.5)$ & $4.4(1.9)$ & $4.5(2.4)$ \\
\hline Throw away something you don't need from the drawer & 33 & $4.3(1.9)$ & $3.9(2.4)$ & $3.6(2.0)$ & $3.5(2.1)$ \\
\hline Go to a coffee shop after lunch & 27 & $8.4(1.8)$ & $8.3(2.2)$ & $8.4(1.8)$ & $8.3(2.1)$ \\
\hline Put some bath powder in the bathtub & 24 & $2.9(2.0)$ & $3.3(2.1)$ & $4.1(2.0)$ & $4.4(2.0)$ \\
\hline Close your eyes for $3 \mathrm{~min}$ & 21 & $2.9(1.7)$ & $2.6(2.2)$ & $2.7(1.1)$ & $2.5(2.3)$ \\
\hline Take a different route on the way back home & 20 & $3.0(1.4)$ & $3.4(2.3)$ & $3.1(1.1)$ & $3.3(2.2)$ \\
\hline
\end{tabular}

${ }^{\mathrm{a}} \mathrm{SD}$ : standard deviation.

Table 4. Behavioral activations: top 10 activities in mastery achieved and their frequencies.

\begin{tabular}{lll}
\hline Activity & Frequency (number of reports) & ${\text { Mastery achieved, mean }\left(\mathrm{SD}^{\mathrm{a}}\right)}$ \\
\hline Test-drive a new car & 3 & $9.7(0.6)$ \\
Go to a coffee shop after lunch & 27 & $8.3(2.2)$ \\
Exercise & 3 & $8.3(2.9)$ \\
Call up an old friend & 4 & $7.8(2.9)$ \\
Go to yoga with a friend & 6 & $7.2(1.2)$ \\
Go to a hairdresser & 3 & $6.7(1.5)$ \\
Go to a gym & 7 & $6.6(3)$ \\
Walking & 8 & $6.5(0.8)$ \\
Get a haircut & 4 & $6.5(3)$ \\
Go to a meal with a friend & 13 & $6.3(2.8)$ \\
\hline
\end{tabular}

${ }^{\mathrm{a}} \mathrm{SD}$ : standard deviation.

Table 5. Behavioral activations: top 10 activities in pleasure achieved and their frequencies.

\begin{tabular}{lll}
\hline Activity & Frequency (number of reports) & Pleasure achieved, mean $\left(\mathrm{SD}^{\mathrm{a}}\right)$ \\
\hline Test-drive a new car & 3 & $9.7(0.6)$ \\
Call up an old friend & 4 & $9.0(1.4)$ \\
Exercise & 3 & $8.7(2.3)$ \\
Go to a coffee shop after lunch & 27 & $8.3(2.1)$ \\
Go to yoga with a friend & 6 & $7.8(1)$ \\
Call up a family and hear their voice & 5 & $7.4(1.5)$ \\
Go to a meal with a friend & 13 & $7.2(2.3)$ \\
Go out for a luxurious lunch & 17 & $6.8(2.9)$ \\
Take a walk & 8 & $6.6(2)$ \\
Nail art & 4 & $6.3(3.8)$ \\
\hline
\end{tabular}

${ }^{\mathrm{a}} \mathrm{SD}$ : standard deviation. 
Some activities brought greater levels of mastery and pleasure than initially expected. Such pleasant surprises included "Exercise," "Do a makeup," "Buy a comic book at a convenience store," "Call up an old friend," or "Go out for a luxurious lunch" (Tables 6 and 7).

\section{Cognitive Restructurings}

All the cognitive restructuring items showed statistically significant reductions in sad or depressed, anxious or worried, or angry feelings when the emotion levels were compared pre-post within each situation that the patient worked on (Table 8). Typically, the level of emotion went down from approximately 3.5 to 2.1 , showing a reduction greater than 1 point, on a scale of 0 to 5 .

When the four tools were compared against each other, again within each situation, friend's call and \% Calculator both outperformed fact glasses. The average change in emotion level was -1.6 (SD 1.3), -1.5 (SD 1.3), -1.4 (SD 1.3), and -1.3 (1.3), respectively, for friend's call, what-now microphone, \% calculator, and fact glasses.

\section{Contrasts Between Beneficiaries and Nonbeneficiaries of Kokoro-App}

The median of the final change score on PHQ-9 was 4 . We therefore split the cohort into beneficiaries from Kokoro-App (change greater than $4: \mathrm{n}=31$ ) and nonbeneficiaries (change of 4 or less: $n=49$, including six who showed deterioration from baseline).

Although the beneficiaries tended to complete more sessions, need fewer days to complete one session, and spent more time per session, the group differences were not statistically significant (Multimedia Appendix 1).

Neither did the numbers of mind maps completed, overall and by emotion differ between the two groups, although the beneficiaries tended to report a slightly higher level of happy emotion.

Table 6. Behavioral activations: top 10 activities in unexpected mastery and their frequencies.

\begin{tabular}{lll}
\hline Activity & Frequency (number of reports) & Mastery achieved-expected, mean $\left(\mathrm{SD}^{\mathrm{a}}\right)$ \\
\hline Exercise & 3 & $1.3(2.3)$ \\
Buy a comic book at a convenience store & 4 & $1.0(1.4)$ \\
Call up an old friend & 3 & $1.0(1.7)$ \\
Do a makeup & 5 & $0.8(1.3)$ \\
Call up a family and hear their voice & 5 & $0.8(1.3)$ \\
Go see a movie & 4 & $0.8(1.0)$ \\
Test-drive a new car & 3 & $0.7(0.6)$ \\
Nail art & 3 & $0.7(2.1)$ \\
Take a long bath & 32 & $0.6(1.7)$ \\
Put some bath powder in the bathtub & 21 & $0.5(1.0)$ \\
\hline
\end{tabular}

${ }^{\mathrm{a}} \mathrm{SD}$ : standard deviation.

Table 7. Behavioral activations: top 10 activities in unexpected pleasure and their frequencies.

\begin{tabular}{lll}
\hline Activity & Frequency (number of reports) & Pleasure achieved-expected, mean $\left(\mathrm{SD}^{\mathrm{a}}\right)$ \\
\hline Do a makeup & 5 & $1.0(1.7)$ \\
Call up an old friend & 3 & $1.0(1.7)$ \\
Test-drive a new car & 3 & $0.7(0.6)$ \\
Go out for a luxurious lunch & 15 & $0.6(1.9)$ \\
Say hurray! & 9 & $0.6(0.7)$ \\
Borrow and watch a DVD & 8 & $0.6(2.7)$ \\
Go to a gym & 7 & $0.6(2.9)$ \\
Put some bath powder in the bathtub & 21 & $0.5(1.0)$ \\
Take a long bath & 31 & $0.4(1.2)$ \\
Throw away something you don't need from the drawer & 25 & $0.4(1.7)$ \\
\hline
\end{tabular}

${ }^{\mathrm{a}} \mathrm{SD}$ : standard deviation. 
Table 8. Changes in emotion levels by cognitive restructuring items. The statistical test was done with within-situation paired $t$ test.

\begin{tabular}{|c|c|c|c|c|}
\hline Item and emotion & Before, mean $\left(\mathrm{SD}^{\mathrm{a}}\right)$ & After, mean (SD) & Change, mean (SD) & $P$ value \\
\hline \multicolumn{5}{|l|}{ Fact glasses } \\
\hline Sad or depressed $(n=68)$ & $3.5(1.3)$ & $2.4(1.3)$ & $-1.5(1.3)$ & $<.001$ \\
\hline Anxious or worried $(n=61)$ & $3.7(1.1)$ & $2.2(1.4)$ & $-1.5(1.2)$ & $<.001$ \\
\hline Angry $(n=44)$ & $3.8(1.2)$ & $2.3(1.3)$ & $-1.1(1.3)$ & $<.001$ \\
\hline \multicolumn{5}{|l|}{$\%$ Calculator } \\
\hline Sad or depressed $(n=48)$ & $3.5(1.3)$ & $2.2(1.2)$ & $-1.3(1.3)$ & $<.001$ \\
\hline Anxious or worried $(n=49)$ & $3.7(1.1)$ & $2.1(1.4)$ & $-1.6(1.2)$ & $<.001$ \\
\hline Angry $(\mathrm{n}=33)$ & $3.8(1.3)$ & $2.2(1.1)$ & $-1.5(1.3)$ & $<.001$ \\
\hline \multicolumn{5}{|l|}{ Friend's call } \\
\hline Sad or depressed $(n=50)$ & $3.6(1.3)$ & $2.1(1.2)$ & $-1.5(1.3)$ & $<.001$ \\
\hline Anxious or worried $(n=46)$ & $3.7(1.2)$ & $2.1(1.2)$ & $-1.7(1.3)$ & $<.001$ \\
\hline Angry $(n=30)$ & $3.4(1.3)$ & $2.0(1.1)$ & $-1.4(1.3)$ & $<.001$ \\
\hline \multicolumn{5}{|l|}{ What-now microphone } \\
\hline Sad or depressed $(n=41)$ & $3.4(1.3)$ & $2.0(1.2)$ & $-1.4(1.3)$ & $<.001$ \\
\hline Anxious or worried $(n=45)$ & $3.9(1.1)$ & $2.1(1.2)$ & $-1.8(1.2)$ & $<.001$ \\
\hline Angry $(n=30)$ & $3.6(1.3)$ & $2.4(1.2)$ & $-1.2(1.3)$ & $<.001$ \\
\hline
\end{tabular}

${ }^{\mathrm{a}} \mathrm{SD}$ : standard deviation.

The use of behavioral activation differed significantly in many aspects between the successful users and the less successful ones. The former conducted almost twice as many behavioral activations and expected and achieved greater levels of mastery or pleasure. The kinds of behavioral activation tasks chosen were significantly different: differences by more than $3 \%$ were found for activities such as "Listen to favorite music," "Read books and magazines," "Go to a coffee shop after lunch" (all more frequent among the beneficiaries), and "Take a long bath" (more frequent among nonbeneficiaries). The time categories of activities chosen were also different: the beneficiaries chose activities likely to require $60 \mathrm{~min}$, whereas the nonbeneficiaries chose activities requiring $5 \mathrm{~min}$ or less.

The successful users of Kokoro-App also conducted more cognitive restructuring than the less successful ones, especially those using fact glasses and \% Calculator. The decrease in emotion levels, however, was significantly different between the two groups only when using \% Calculator.

\section{Discussion}

\section{Summary of Findings}

Kokoro-App was well accepted among the patients who had been unresponsive to one or more antidepressants and were moderately to severely depressed at baseline. The patients proceeded with the sessions in Kokoro-App at their own pace, spending approximately $60 \mathrm{~min}$ across 10 days for each session. Over the course of 9 weeks, on average, they completed 10 mind maps for self-monitoring own emotions and thoughts, conducted 14 behavioral activation personal experiments, and filled in six cognitive restructuring worksheets.
To the best of our knowledge, this study is the first study to examine specific details of behavioral activation or cognitive restructuring tasks conducted by the patients undergoing remote CBT or face-to-face CBT among a sizable number of clinical patients. Very interesting pictures emerged. Although patients often conducted activities with expected and achieved mastery or pleasure levels, around 4 to 5, a number of candidate activities emerged that achieved higher than expected mastery or pleasure. Such activities included, among others, "Test-drive a new car," "Go to a coffee shop after lunch," "Exercise," "Call up an old friend," "Do a makeup," and "Go out for a luxurious lunch." All the cognitive restructuring items were able to reduce the emotion levels significantly.

The study is also the first to compare details of the behavioral and cognitive skills practiced by the patients with regard to the outcome. The successful users of Kokoro-App conducted twice as many behavioral experiments of different kinds and of different time requirements than those who were less successful. The former also conducted significantly more cognitive restructuring tasks, especially using \% Calculator.

\section{Limitations of the Study}

These are several caveats in the interpretation of the current findings. First, although the original study was an RCT examining the value of adjunctive use of Kokoro-App, this study is by nature an observational study of the users of Kokoro-App. The current results therefore indicate association but not necessarily causation. The amount and nature of behavioral activation tasks or cognitive restructuring worksheets are potential mediators in the causative process from using the smartphone CBT to reduction in depressive symptomatology. It is possible that the beneficiaries of Kokoro-App got better 
because they engaged in more behavioral activations, or it is also possible that they conducted more behavioral activations because they had already felt better and had more energy. Second, in accordance with the observational nature of the study, we did not correct for multiple statistical testing and the analyses remain hypothesis-generating rather than confirmatory. The insights gained need be examined in future confirmatory experiments to provide ultimate guidance on how to conduct CBT. Third, strictly speaking, the findings only apply to Kokoro-App and the Japanese patients with moderate to severe depression on an antidepressant treatment. Whether they would apply to other smartphone or Internet CBT (iCBT), or whether they apply to Japanese nonclinical populations or to non-Japanese patients when they use Kokoro-App cannot be taken for granted. For example, "Take a long bath" or "Put some bath powder in the bathtub" may be particularly comforting for the Japanese people who traditionally take great pleasure in taking baths and may not necessarily apply to people living in different cultural traditions. The candidate activities list must certainly be culturally adapted when Kokoro-App is transferred to different countries. It must also be emphasized that app contents need be contextualized for each user's age, sex, personal relationships, disabilities, and so on to make them more specific.

\section{Implications of the Study Findings}

Nonetheless, our findings have important implications at three levels. First, they suggest how Kokoro-App can be improved in the next upgrade. Currently Kokoro-App lists the candidate activities according to the number of "Nice!"s that the patients have voted. This is probably a good feature of the app, creating an atmosphere of a therapeutic community. The next version of Kokoro-App can probably add another dimension to the recommendation by highlighting such activities that may not have been experimented by many but which turned out to produce great mastery or pleasure. The next version of Kokoro-App may also choose to emphasize \% Calculator, and possibly do away with fact glasses as the latter has been found to be less effective than the other items. \% Calculator and fact glasses aim to derive the same kinds of information, namely evidence for and evidence against the automatic thoughts but through different Socratic questions. \% Calculator may be easier to understand for the users.

Second, they provide some insight on how iCBT and CBT in general can be better practiced. Our results suggest that behavioral activation best distinguishes the more from the less successful users of smartphone CBT. This finding is in line with a growing number of RCTs showing similar effectiveness of behavioral activation in comparison with the full CBT package, including cognitive restructuring [7-9]. However, these studies compared the different versions of CBT in the face-to-face settings. Whether the iCBT may as well consist only of behavioral activation or need to include cognitive restructuring is an empirical question warranting a direct randomized comparison.

Third, they also provide suggestions for the next generation of mobile health (mHealth). Providing the mHealth intervention on the Web or via a smartphone increases accessibility of the intervention but is only taking advantage of one aspect of the technology. The program can be used to collect valuable information of what the users of the program do or feel. It may also be combined with habit formation activities. Development of such an e-monitoring system has its own difficulties and complexities, including privacy, integration, and customization [21] but our Kokoro-Web presents one successful example and our study an example of how such a system enables collection of important and fertile information.

\section{Acknowledgments}

The study was funded by the Ministry of Health, Labor, and Welfare, Japan (H-22-Seishin-Ippan-008) from April 2013 to March 2014 and thereafter by the Japan Foundation for Neuroscience and Mental Health (JFNMH). The JFNMH received donations from Asahi Kasei, Eli-Lilly, GSK, Janssen, MSD, Meiji Seika, Mitsubishi-Tanabe, Mochida, Otsuka, Pfizer, Shionogi, and Taisho. The study was supported in part by JSPS KAKENHI (Grant-in-Aid for Scientific Research) grant number 17K19808 to TAF. A complete list of participating centers and investigators in the Fun to Learn to Act and Think through Technology (FLATT) trial appears in Multimedia Appendix 2.

\section{Authors' Contributions}

TAF conceived the study. TAF, MH, and NY designed the study. KF, NT, RJ, YK, SO, HS, NK, YS, YI, HI, AT, YO, NT, TA, MY, SS, NW, MI, and AH carried out the study. TAF conducted the analyses and wrote the first draft manuscript. All authors contributed to the critical revision of the draft and read and approved the final manuscript.

\section{Conflicts of Interest}

TAF has received lecture fees from Eli Lilly, Janssen, Meiji, MSD, Otsuka, Pfizer, and Tanabe-Mitsubishi and consultancy fees from Takeda Science Foundation. He has received royalties from Igaku-Shoin and Nihon Bunka Kagaku-sha publishers. He has received research support from Mochida and Tanabe-Mitsubishi. He is diplomate of the Academy of Cognitive Therapy. MH has received royalties from Igaku Shoin, Shogakukan Shuei-sha Production, Shindan-to-Chiryo-sha, Sogen-sha, Kango-Kyokai, Kitaoji-Shobo, and Kongo-Shuppan publishers. HF has received lecture fees from Meiji and Mochida. NT has received speaking fees from Astellas, Shionogi, Novartis, FUJIFILM RI Pharma, Meiji, Mochida, Janssen, Eli Lilly, and Dainippon-Sumitomo. He has received royalties from Igaku-Shoin, Nanzando, Medical View, and Kanehara publishers. YK has received speaking fee from Otsuka, Yoshitomi, Tanabe-Mitsubishi, Dainippon-Sumitomo, and Eli Lilly. SO has received speaking fee from Eli Lilly and Mochida. He has received royalties from Igaku-Shoin and Nihon-Hyoron-sha publishers. NK has received lecture fees from Eli 
Lilly, Janssen, Dainippon-Sumitomo, and Otsuka and consultancy fees from Meiji and Otsuka. He has received royalties from Igaku-Shoin, Nakayama-Shoten, Seronjihou-sha, and Iwasakigakujutu-Shuppan publishers. He has received research funds from Shionogi, Pfizer, and Meiji-Seika. YO has received honoraria for speaking at meetings sponsored by Eli Lilly. NT has received lecture fees from Otsuka and Meiji. AT has received honoraria for speaking at a meeting sponsored by Eli Lilly and Tanabe-Mitsubishi. He has received royalties from Kagaku-Hyoron-sha. TA has received speaking fees or research funds from Daiichi-Sankyo, Eizai, Hisamitsu, Lilly, MSD, Meiji, Mochida, Otsuka, Pfizer, Novartis, and Terumo. He has received royalties from Igaku-Shoin, Nanzando, and Nankodo publishers. MY has received speaking fees from Meiji and has contracted research with Nippon Chemiphar. MI has received lecture fees from Pfizer, Mochida, Shionogi, Daiichi-Sankyo, Meiji, Takeda, and Sumitomo Dainippon Pharma. He has received royalties from Nippon-Hyoron-Sha, Nanzando, Seiwa-Shoten, Igaku-Shoin, and Technomics. SS has received lecture fees from Otsuka, MSD, Meiji, Eli Lilly, Mochida, Pfizer, and Tanabe-Mitsubishi. He has received royalties from Seiwa-Shoten. He has received royalties from Sentan-Igaku-sha, Chuohoki, and Medical Review publishers. NW has received royalties from Sogen-sha, Paquet and Akatsuki publishers.

\section{Multimedia Appendix 1}

Beneficiaries and nonbeneficiaries of Kokoro-App.

[PDF File (Adobe PDF File), 63KB-Multimedia Appendix 1]

\section{Multimedia Appendix 2}

FLATT investigators and committee members.

[PDF File (Adobe PDF File), 29KB-Multimedia Appendix 2]

\section{References}

1. Cuijpers P, van Straten A, Andersson G, van Oppen P. Psychotherapy for depression in adults: a meta-analysis of comparative outcome studies. J Consult Clin Psychol 2008 Dec;76(6):909-922. [doi: 10.1037/a0013075] [Medline: 19045960]

2. Baardseth TP, Goldberg SB, Pace BT, Wislocki AP, Frost ND, Siddiqui JR, et al. Cognitive-behavioral therapy versus other therapies: redux. Clin Psychol Rev 2013 Apr;33(3):395-405. [doi: 10.1016/j.cpr.2013.01.004] [Medline: 23416876]

3. Barth J, Munder T, Gerger H, Nüesch E, Trelle S, Znoj H, et al. Comparative efficacy of seven psychotherapeutic interventions for patients with depression: a network meta-analysis. PLoS Med 2013;10(5):e1001454 [FREE Full text] [doi: 10.1371/journal.pmed.1001454] [Medline: 23723742]

4. Furukawa TA, Weitz ES, Tanaka S, Hollon SD, Hofmann SG, Andersson G, et al. Initial severity of depression and efficacy of cognitive-behavioural therapy: individual-participant data meta-analysis of pill-placebo-controlled trials. Br J Psychiatry 2017 Mar;210(3):190-196. [doi: 10.1192/bjp.bp.116.187773] [Medline: 28104735]

5. Weitz ES, Hollon SD, Twisk J, van Straten A, Huibers MJH, David D, et al. Baseline depression severity as moderator of depression outcomes between cognitive behavioral therapy vs pharmacotherapy: an individual patient data meta-analysis. JAMA Psychiatry 2015 Nov;72(11):1102-1109. [doi: 10.1001/jamapsychiatry.2015.1516] [Medline: 26397232]

6. Churchill R, Moore T, Caldwell D, Davies P, Jones H, Furukawa T, et al. Cognitive behavioural therapies versus other psychological therapies for depression. Cochrane Database Syst Rev 2010(9) [FREE Full text] [doi:

10.1002/14651858.CD008698] [Medline: 25411559]

7. Jacobson NS, Dobson KS, Truax PA, Addis ME, Koerner K, Gollan JK, et al. A component analysis of cognitive-behavioral treatment for depression. J Consult Clin Psychol 1996 Apr;64(2):295-304. [Medline: 8871414]

8. Dimidjian S, Hollon SD, Dobson KS, Schmaling KB, Kohlenberg RJ, Addis ME, et al. Randomized trial of behavioral activation, cognitive therapy, and antidepressant medication in the acute treatment of adults with major depression. J Consult Clin Psychol 2006 Aug;74(4):658-670. [doi: 10.1037/0022-006X.74.4.658] [Medline: 16881773]

9. Richards DA, Ekers D, McMillan D, Taylor RS, Byford S, Warren FC, et al. Cost and outcome of behavioural activation versus Cognitive Behavioural Therapy for Depression (COBRA): a randomised, controlled, non-inferiority trial. Lancet 2016 Aug 27;388(10047):871-880 [FREE Full text] [doi: 10.1016/S0140-6736(16)31140-0] [Medline: 27461440]

10. Cuijpers P. Are all psychotherapies equally effective in the treatment of adult depression? The lack of statistical power of comparative outcome studies. Evid Based Ment Health 2016 Dec;19(2):39-42. [doi: 10.1136/eb-2016-102341] [Medline: $\underline{26984413}]$

11. Bell EC, Marcus DK, Goodlad JK. Are the parts as good as the whole? A meta-analysis of component treatment studies. J Consult Clin Psychol 2013 Aug;81(4):722-736. [doi: 10.1037/a0033004] [Medline: 23688145]

12. Karyotaki E, Riper H, Twisk J, Hoogendoorn A, Kleiboer A, Mira A, et al. Efficacy of self-guided internet-based Cognitive Behavioral Therapy in the treatment of depressive symptoms: a meta-analysis of individual participant data. JAMA Psychiatry 2017 Apr 01;74(4):351-359. [doi: 10.1001/jamapsychiatry.2017.0044] [Medline: 28241179] 
13. Donker T, Petrie K, Proudfoot J, Clarke J, Birch M, Christensen H. Smartphones for smarter delivery of mental health programs: a systematic review. J Med Internet Res 2013;15(11):e247 [FREE Full text] [doi: 10.2196/jmir.2791] [Medline: 24240579]

14. Eysenbach G, CONSORT-EHEALTH Group. CONSORT-EHEALTH: improving and standardizing evaluation reports of web-based and mobile health interventions. J Med Internet Res 2011;13(4):e126 [FREE Full text] [doi: 10.2196/jmir.1923] [Medline: 22209829]

15. Armey MF, Schatten HT, Haradhvala N, Miller IW. Ecological momentary assessment (EMA) of depression-related phenomena. Curr Opin Psychol 2015 Aug 1;4:21-25. [doi: 10.1016/j.copsyc.2015.01.002] [Medline: 25664334]

16. aan het Rot M, Hogenelst K, Schoevers RA. Mood disorders in everyday life: a systematic review of experience sampling and ecological momentary assessment studies. Clin Psychol Rev 2012 Aug;32(6):510-523. [doi: 10.1016/j.cpr.2012.05.007] [Medline: 22721999]

17. Mantani A, Kato T, Furukawa TA, Horikoshi M, Imai H, Hiroe T, et al. Smartphone cognitive-behavior therapy as adjunct to pharmacotherapy for refractory depression: a randomized controlled trial. J Med Internet Res 2017 Nov 03;19(11):e373 [FREE Full text] [doi: 10.2196/jmir.8602] [Medline: 29101095]

18. Thase ME, Rush AJ. When at first you don't succeed: sequential strategies for antidepressant nonresponders. J Clin Psychiatry 1997;58(Suppl 13):23-29 [FREE Full text] [Medline: 9402916]

19. Spitzer RL, Kroenke K, Williams JB. Validation and utility of a self-report version of PRIME-MD: the PHQ primary care study. Primary care evaluation of mental disorders. Patient Health Questionnaire. J Am Med Assoc 1999 Nov 10;282(18):1737-1744. [Medline: 10568646$]$

20. Beck A, Steer R, Brown G. BDI-II: Beck Depression Inventory, Second Edition. San Antonia: The Psychological Corporation; 1996.

21. Sundram F, Hawken SJ, Stasiak K, Lucassen MF, Fleming T, Shepherd M, et al. Tips and traps: lessons from codesigning a clinician e-monitoring tool for computerized cognitive behavioral therapy. JMIR Ment Health 2017 Jan 11;4(1):e3 [FRE Full text] [doi: 10.2196/mental.5878] [Medline: 28077345]

\author{
Abbreviations \\ CBT: cognitive behavioral therapy \\ iCBT: Internet cognitive behavioral therapy \\ mHealth: mobile health \\ SD: standard deviation
}

Edited by G Eysenbach; submitted 03.10.17; peer-reviewed by N Bragazzi, S Aggarwal; comments to author 08.11.17; revised version
received 16.11.17; accepted 17.11.17; published 11.01 .18
Please cite as:
Furukawa TA, Horikoshi M, Fujita H, Tsujino N, Jinnin R, Kako Y, Ogawa S, Sato H, Kitagawa N, Shinagawa Y, Ikeda Y, Imai H,
Tajika A, Ogawa Y, Akechi T, Yamada M, Shimodera S, Watanabe N, Inagaki M, Hasegawa A
Cognitive and Behavioral Skills Exercises Completed by Patients with Major Depression During Smartphone Cognitive Behavioral
Therapy: Secondary Analysis of a Randomized Controlled Trial
JMIR Ment Health 2018;5(1):e4
URL: http://mental.jmir.org/2018/1/e4/
doi: $10.2196 /$ mental.9092
PMID: 29326098

(C)Toshi A Furukawa, Masaru Horikoshi, Hirokazu Fujita, Naohisa Tsujino, Ran Jinnin, Yuki Kako, Sei Ogawa, Hirotoshi Sato, Nobuki Kitagawa, Yoshihiro Shinagawa, Yoshio Ikeda, Hissei Imai, Aran Tajika, Yusuke Ogawa, Tatsuo Akechi, Mitsuhiko Yamada, Shinji Shimodera, Norio Watanabe, Masatoshi Inagaki, Akio Hasegawa. Originally published in JMIR Mental Health (http://mental.jmir.org), 11.01.2018. This is an open-access article distributed under the terms of the Creative Commons Attribution License (https://creativecommons.org/licenses/by/4.0/), which permits unrestricted use, distribution, and reproduction in any medium, provided the original work, first published in JMIR Mental Health, is properly cited. The complete bibliographic information, a link to the original publication on http://mental.jmir.org/, as well as this copyright and license information must be included. 